\title{
Regular Exercise Prolongs Survival in a Type 2 Spinal Muscular Atrophy Model Mouse
}

\author{
Clément Grondard, ${ }^{1}$ Olivier Biondi, ${ }^{1}$ Anne-Sophie Armand, ${ }^{1}$ Sylvie Lécolle, ${ }^{1}$ Bruno Della Gaspera, ${ }^{1}$ Claude Pariset, ${ }^{1}$ \\ Hung Li, ${ }^{2}$ Claude-Louis Gallien, ${ }^{1}$ Pierre-Paul Vidal, ${ }^{1}$ Christophe Chanoine, ${ }^{1}$ and Frédéric Charbonnier ${ }^{1}$ \\ ${ }^{1}$ Université Paris Descartes, Centre Universitaire des Saints-Pères, Laboratoire de Neurobiologie des Réseaux Sensorimoteurs, Unité Mixte de Recherche \\ 7060, Centre National de la Recherche Scientifique, Equipe Biologie du Développement et de la Différenciation Neuromusculaire, F-75270 Paris, France, and \\ ${ }^{2}$ Institute of Molecular Biology, Academia Sinica, Nankang, Taipei 115, Taiwan
}

\begin{abstract}
Several studies indicate that physical exercise is likely to be neuroprotective, even in the case of neuromuscular disease. In the present work, we evaluated the efficiency of running-based training on type 2 spinal muscular atrophy (SMA)-like mice. The model used in this study is an SMN (survival motor neuron)-null mouse carrying one copy of a transgene of human SMN2. The running-induced benefits sustained the motor function and the life span of the type 2 SMA-like mice by $57.3 \%$. We showed that the extent of neuronal death is reduced in the lumbar anterior horn of the spinal cord of running-trained mice in comparison with untrained animals. Notably, exercise enhanced motoneuron survival. We showed that the running-mediated neuroprotection is related to a change of the alternative splicing pattern of exon 7 in the SMN2 gene, leading to increased amounts of exon 7-containing transcripts in the spinal cord of trained mice. In addition, analysis at the level of two muscles from the calf, the slow-twitch soleus and the fast-twitch plantaris, showed an overall conserved muscle phenotype in running-trained animals. These data provide the first evidence for the beneficial effect of exercise in SMA and might lead to important therapeutic developments for human SMA patients.
\end{abstract}

Key words: spinal muscular atrophy; exercise; mouse model; neuroprotection; alternative splicing; muscular phenotype

\section{Introduction}

Spinal muscular atrophy (SMA) is a neurodegenerative disease characterized by the loss of spinal cord motoneurons. SMA represents a common genetic cause of death in childhood. Three types of SMA are commonly distinguished by their onset, time course, and degree of motor function loss. Molecular analysis has shown that both of the severe SMA types, i.e., the early-onset form (type 1) and the mild late-onset form (type 2), are linked to the same locus on chromosome 5, where the SMN (survival motor neuron) gene is duplicated in an inverted repeat (Lewin, 1995). Deletion or mutation of the telomeric copy of the SMN gene (SMN1) causes SMA (Lefebvre et al., 1995). The expression of SMN protein encoded by the centromeric SMN gene (SMN2) can only partially compensate the lack of $S M N 1$ function. Indeed, the predominant SMN form encoded by SMN2 lacks the C terminus because of alternative splicing of exon 7 (Lorson et al., 1998), representing an unstable protein (Lorson and Androphy, 2000). Thus, increasing the amount of full-length SMN protein in SMA spinal cord may have beneficial effects in the disease.

Received March 31, 2005; revised June 6, 2005; accepted July 2, 2005.

This work was supported in part by the Centre National de la Recherche Scientifique and by grants from the Association Française contre les Myopathies. C.G. is a recipient of a doctoral fellowship from the Ministere de I'Education Nationale et de la Recherche. We thank R. Cassada for critical reading of this manuscript.

Correspondence should be addressed to Frédéric Charbonnier, Université Paris Descartes, Centre Universitaire des Saints-Pères, Laboratoire de Neurobiologie des Réseaux Sensorimoteurs, Unité Mixte de Recherche 7060, Centre National de la Recherche Scientifique, Equipe Biologie du Développement et de la Différenciation Neuromusculaire, F-75270 Paris Cedex 06, France. E-mail: charbonnier@biomedicale.univ-paris5.fr.

D01:10.1523/JNEUROSCI.1245-05.2005

Copyright $\odot 2005$ Society for Neuroscience $\quad$ 0270-6474/05/257615-08\$15.00/0
No specific therapy is presently available for SMA. Treatment is usually supportive, and the most important aim in the management of the patients is to prevent the development of complications. Thus, identifying new therapeutic strategies is of a paramount importance. Many studies have been devoted to the effect of physical exercise on neurological disorders. Clinical observations confirm the efficiency of exercise in alleviating the symptoms in a variety of neurodegenerative diseases and, more specifically, neuromuscular disease such as amyotrophic lateral sclerosis (Kirkinezos et al., 2003; Veldink et al., 2003; Liebetanz et al., 2004; Mahoney et al., 2004). The potential rehabilitative role of exercise training has not been addressed in SMA.

Hsieh-Li et al. (2000) have developed an SMA mouse model, deficient for mouse SMN and expressing a human SMN2 transgene that genetically and phenotypically mimics human SMA. Three different phenotypes of SMA-like mice, i.e., types 1-3, have been correlated with the SMN2 transgene copy number. Thus, the severity of pathology in these mice was shown to be strongly correlated with the amount of intact SMN protein in the spinal cord (Hsieh-Li et al., 2000). These mice display characteristics that meet with the requirements of setting exercise training. Thus, although the onset of type 2 SMA in these mice is very early, resembling the human disease, the mutant mice reach an age at which they are trainable during a sufficient time to detect the effects of exercise on the disease progression and on survival. In addition, in these mice, the splicing pattern of the human transgene SMN2 is similar to the situation in SMA patients. Most SMN transcripts lack exon 7 in the severe type of SMA-like mice 
(Hsieh-Li et al., 2000). Whether exercise could modify the splicing pattern of SMN2 in SMA-like mice is an important question. In the present study, we selected breeder mice that gave only type 2 SMA-like mice and examined whether physical exercise is beneficial to these mice.

\section{Materials and Methods}

Mice. The knock-out transgenic SMA-like mice $\left(S m n^{-1-}\right.$ SMN2) were generated by crossing mice heterozygous for a knock-out of the Smn locus $\left(S m n^{+/-}\right)$with mice heterozygous for a knock-out of the Smn locus containing a human SMN2 transgene $\left(\mathrm{Smn}^{+/-} \mathrm{SMN2}\right)$. These mouse strains were obtained from The Institute of Molecular Biology (Academia Sinica, Taipei, Taiwan). Semiquantitative multiplex PCR was performed for the determination of the number of copies of the SMN2 transgene in $S m n^{+/-} S M N 2$ mice used for crossing with $S m n^{+/-}$mice. A Fam-tagged fluorescently labeled forward primer for the SMN2 gene [5'-(Fam)CGAATCACTTGAGGGCAGGAGTTTG-3' and 5'-AACTGGTGGACATGGCTGTTCATTG-3'] has been optimized for multiplexing along with the mouse IL2 (interleukin 2) gene $\left[5^{\prime}-\right.$ (Fam)CTAGGCCACAGAATTGAAAGATCT-3' and 5'-GTAGGTGGAAATTCTAGCATCATCC- $3^{\prime}$ ] as an internal control. PCR amplification in the log linear range allows quantitative assessment of the product. The conditions for the PCR were as follows: $95^{\circ} \mathrm{C}$ for $5 \mathrm{~min}$ (one cycle) and $95^{\circ} \mathrm{C}$ for $1 \mathrm{~min}, 60^{\circ} \mathrm{C}$ for $1 \mathrm{~min}$, and $72^{\circ} \mathrm{C}$ for $1 \mathrm{~min}(22$ cycles). PCR products were analyzed using an ABI 3100 Sequencer with Genotyper software (Applied Biosystems, Foster City, CA). The transgene copy number was calculated by dividing SMN2 peak height by that obtained for the control (supplemental Fig. 1, available at www.jneurosci.org as supplemental material). Ten females heterozygous for the knock-out of the Smn locus $\left(S m n^{+-}\right)$and carrying only one copy of the SMN2 transgene were bred with male $S m n^{+/-}$mice. The offspring were genotyped by PCR assay of DNA obtained from tail tissue, as described previously (Hsieh-Li et al., 2000), and SMA-like mice were classified as types 1-3 at $10 \mathrm{~d}$ of age based on their phenotype, particularly on their age of survival (Hsieh-Li et al., 2000). The progeny of each crossing are presented in supplemental Figure 1 (available at www.jneurosci.org as supplemental material). Ten crosses gave only type 2 SMA-like mice, which were used for the study. To further confirm the phenotype of the type 2 SMA-like mice, a sample of the spinal cord was systematically taken at the end of each experiment. These samples were analyzed by reverse transcription (RT)-PCR to evaluate the amount of full-length SMN transcript (supplemental Fig. 1, available at www.jneurosci.org as supplemental material).

An untrained group of 45 and a trained group of 45 type 2 SMA-like mice were randomly constituted in a blind systematic manner to minimize bias. The control mice were heterozygous knock-out for Smn with the human SMN2 transgene $\left(S m n^{+/-} S M N 2 ; n=35\right)$. Mortality was scored when mice were unable to right themselves $20 \mathrm{~s}$ after having been placed on their sides.

Training protocol. Exercise was performed in a wheel with a controlled speed. The protocol was started at $10 \mathrm{~d}$ of age. The mice in the trained group were progressively accustomed to wheel training for $2 \mathrm{~d}$ (the first day, four periods of $5 \mathrm{~min}$ running with a rest period of $30 \mathrm{~min}$; the second day, two periods of $10 \mathrm{~min}$ running with a rest period of $30 \mathrm{~min}$ ). Then, the mice were trained continuously, individually for $20 \mathrm{~min} / \mathrm{d}$. The speed was fixed at $2 \mathrm{~m} / \mathrm{min}$ for the first $3 \mathrm{~d}$ and then increased in steps of $1 \mathrm{~m} / \mathrm{min}$ to finally attain $5 \mathrm{~m} / \mathrm{min}$ (maximal speed). The mice ran $40 \mathrm{~m}$ the first $3 \mathrm{~d}, 60 \mathrm{~m}$ the fourth day, $80 \mathrm{~m}$ the fifth day, and $100 \mathrm{~m}$ from the sixth day.

Assay of strength in type 2 SMA-like mice. Type 2 SMA-like mice were tested to evaluate the forelimb grip strength. All of the tests were made blind, the group assignment being unknown to the observers. Control mice as well as untrained and trained type 2 SMA-like mice between 10 and $15 \mathrm{~d}$ of age were timed for how long they could support their weight holding onto a metal rail suspended in midair. Each mouse was subjected to five trials with at least a $10 \mathrm{~min}$ rest period between tests.

Open field. The ambulatory behavior was assessed in an open-field test. The apparatus consisted of a wooden box measuring $28 \times 28 \times 5 \mathrm{~cm}$. The floor of the arena was divided into 16 equal squares of $7 \times 7 \mathrm{~cm}$.
Squares adjacent to walls were referred to as periphery, and the four remaining squares were referred to as center. The mice were tested individually, and the open field was washed after each session. Each mouse was placed in a central square of the open field. It was allowed to move freely for $5 \mathrm{~min}$, and data were scored manually by the experimenter. The behavioral measures recorded during these $5 \mathrm{~min}$ were the number of peripheral and central square crossings and the percentage of peripheral crossing.

Histological analysis and counting motoneurons. The mice were anesthetized with chloral hydrate (3\%). The lumbar region of the spinal cord (L1-L5) was processed for paraffin embedding. Two hundred twentyfive serial cross sections (12 $\mu \mathrm{m}$ thickness) of the lumbar spinal cords were made ( $2700 \mu \mathrm{m}$ total length), among which one of every five sections (45 sections examined) was processed and Nissl-stained, as reported previously (Klivenyi et al., 1999). The sections were analyzed at a $200 \times$ magnification in the anterior horn (either left or right) for the presence of all neurons in that region. All cells were counted within the ventral horn below an arbitrary horizontal line drawn from the central canal. Only neuronal cells showing at least one nucleolus located within the nucleus were counted. Cell counts were performed using ImageJ software (National Institutes of Health, Bethesda, MD) on images captured electronically.

Immunohistochemical analysis. Spinal cord serial sections, $50 \mu \mathrm{m}$ thick, were cut between L1 and L5 on a sliding microtome, collected in PBS, and processed as free-floating sections. Tissue sections were incubated for $30 \mathrm{~min}$ at room temperature in a blocking solution (4\% normal donkey serum with $0.3 \%$ Triton X-100 in PBS) and then incubated overnight at room temperature in the primary antiserum.

Immunostaining using choline acetyltransferase (ChAT) (polyclonal rabbit anti-ChAT; 1:400; Chemicon, Temecula, CA) was used to stain motoneurons in the spinal cord sections. After incubation, tissue sections were washed three times for $10 \mathrm{~min}$ in PBS and incubated in the secondary antibody solution (Alexa Fluor 488 donkey anti-rabbit IgG; 1:400; Molecular Probes, Eugene, OR) for $2 \mathrm{~h}$ at room temperature.

Immunohistohistochemical detection of SMN protein was performed using a monoclonal antibody raised against full-length human SMN protein (1:200; clone 2B1; ImmuQuest, Cleveland, UK) and the purified rabbit polyclonal antibody $\mathrm{H} 2$, described previously (1:200) (Chang et al., 2001). Sections were washed between every subsequent step with PBS. Endogenous peroxidase activity was blocked by incubating the sections in $3 \% \mathrm{H}_{2} \mathrm{O}_{2}$ (diluted in PBS) for $30 \mathrm{~min}$. Sections were subsequently incubated for $30 \mathrm{~min}$ with a biotinylated fragment of goat anti-rabbit and goat anti-mouse Ig (1:400; DakoCytomation, High Wycombe, UK), followed by horseradish peroxidase-conjugated streptavidin (DakoCytomation) and developed with DAB (DakoCytomation) chromogen to the specifications of the manufacturer.

Finally, the sections were washed three times for $10 \mathrm{~min}$ in PBS and mounted in Vectashield mounting medium (Vector Laboratories, Burlingame, CA). The staining specificity was checked in control incubations performed in the absence of the primary antibody. Motoneuron counts and areas were evaluated using ImageJ software.

Retrograde labeling of motoneurons projecting in soleus and plantaris muscles. Ten-day-old mice were anesthetized with isoflurane (Laboratoire Mundipharma, Boulogne Billancourt, France). A small incision was made in the left calf skin to expose the soleus and plantaris muscles. A total volume of $50 \mathrm{nl}$ of fluorogold (Fluorochrome, Denver, CO) in PBS was injected in three different parts of each muscle (median, proximal, and distal) using an oil-based microinjector (Nanoject; Drummond Scientific, Broomall, PA). The skin was thereafter sutured with a 6-0 polyamide thread (Supramid; S. Jackson, Alexandria, VA), and the mice were kept at $35^{\circ} \mathrm{C}$ until recovery from narcosis. They were then returned to their cage, in which all animals were given food and water ad libitum. At $13 \mathrm{~d}$ of age, mice were perfused and processed for histological analysis.

Apoptosis evaluation. The apoptotic nuclei were observed after terminal deoxynucleotidyl transferase-mediated biotinylated UTP nick endlabeling (TUNEL) staining. Segments (L1-L5) embedded in paraffin were serially sectioned at $12 \mu \mathrm{m}$ thickness. After deparaffinization and rehydration, the sections were digested for $30 \mathrm{~min}$ at $37^{\circ} \mathrm{C}$ in proteinase $\mathrm{K}$ $(20 \mu \mathrm{g} / \mathrm{ml})$. Positive control sections from control animals were incu- 
a)

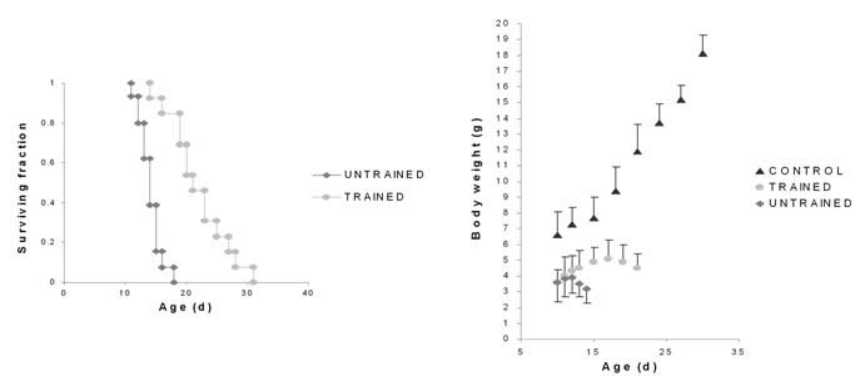

Figure 1. Survival and growth curves of untrained and trained type 2 SMA-like mice. $\boldsymbol{a}$ Survival time of type 2 SMA-like mice after training shown in a Kaplan-Meier survival curve. Fifteen mice were left untrained, and 13 mice were trained from $10 \mathrm{~d}$ of age. The trained type 2 SMA-like mice lived significantly longer than the untrained type 2SMA-like mice $(p<0.001)$. Untrained type 2 SMA-like mice group: mean, $13.7 \mathrm{~d}$; range, $10-18 \mathrm{~d}$; trained type 2 SMA-like mice group: mean, $21.6 \mathrm{~d}$; range, $13-31$ d. $\boldsymbol{b}$, Postnatal growth curves of control mice and trained and untrained type 2 SMA-like mice. A significant difference can be observed between untrained and trained type 2SMA-like mice from $13 \mathrm{~d}$ ( $p<0.001$; control group, $n=15$ mice; untrained type 2 SMA-like mouse group, $n=15$ mice; trained type 2 SMA-like mouse group, $n=13$ mice).

bated in DNase I $(1 \mathrm{U} / 10 \mu \mathrm{l})$ for $10 \mathrm{~min}$ at $37^{\circ} \mathrm{C}$. Tissue sections were then processed for TUNEL staining with an in situ cell death detection kit (Roche Diagnostics, Mannheim, Germany) according to the directions of the manufacturer. Fluorescein-dUTP was used to label DNA strand breaks. For nuclear staining, sections were mounted in Vectashield mounting medium with 4',6-diamidino-2-phenylindole (DAPI) (final concentration, $1.5 \mu \mathrm{g} / \mathrm{ml}$ ) after TUNEL staining. TUNEL-positive cells were counted at a $400 \times$ magnification on 20 sections (spanning a total interval of $2700 \mu \mathrm{m}$ ) of the lumbar spinal cord of each mouse. These counts were then compared with the total number of nuclei determined after DAPI staining.

Semiquantitative and real-time RT-PCR assays. RNA was isolated using the Qiagen (Valencia, CA) RNeasy Mini kit according to the instructions of the manufacturer. RNA was treated with $1 \mathrm{U}$ of amplification-grade

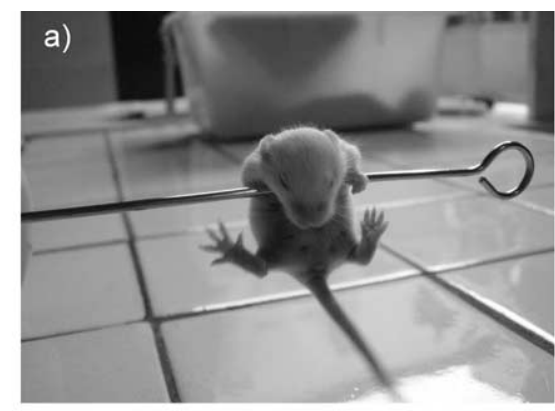

c)

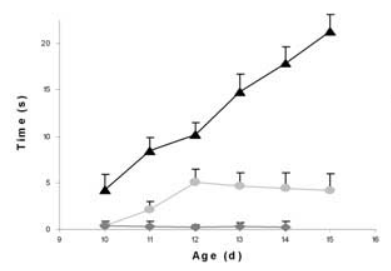

d)
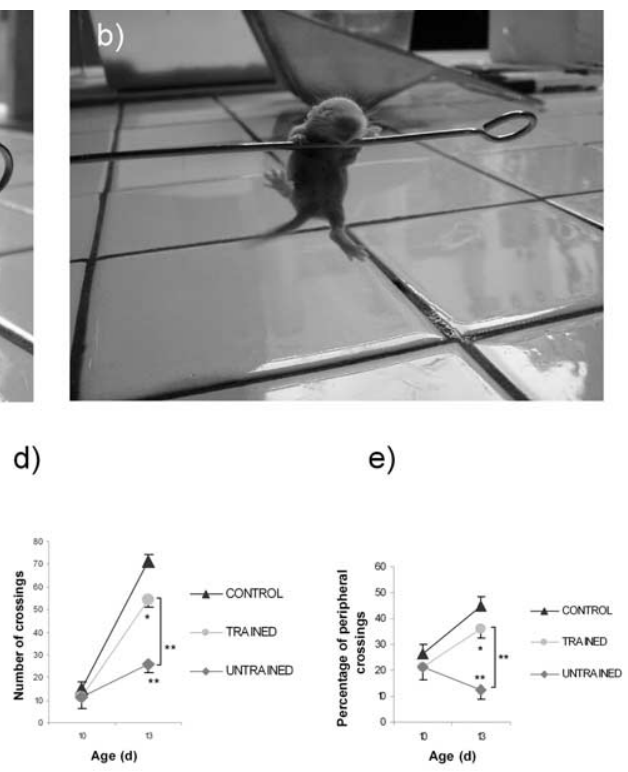

Figure 2. Motor behavior of control, untrained, and trained type 2 SMA-like mice. $\boldsymbol{a}, \boldsymbol{b}$, Grip assay of control $(\boldsymbol{a})$ and trained type 2 SMA-like (b) mice. $\boldsymbol{c}$, Time of grip strength in control, untrained, and trained type 2 SMA-like mice $(n=15,15$, and 13 , respectively). The time that they could support their body weight by holding onto a pencil suspended in the air was statistically different from $11 \mathrm{~d}$ of age between the untrained and the trained type 2SMA-like mice $(p<0.01)$. $\boldsymbol{d}$, $\boldsymbol{e}$, Number of crossings ( $\boldsymbol{d})$ and percentage of peripheral crossings $(\boldsymbol{e})$ in the open-field test in control, untrained, and trained type 2 SMA-like mice ${ }^{* *} p<$ $0.01 ;{ }^{*} p<0.05 ; n=15,15$, and 13 , respectively). deoxyribonuclease I (Invitrogen, San Diego, CA) per microgram of RNA to remove genomic DNA, according to the instructions of the manufacturer. Then, $0.5 \mu \mathrm{g}$ of the RNA was reverse-transcribed using Superscript II reverse transcriptase (Invitrogen) and treated with $\mathrm{RNase} \mathrm{H}$, according to the instructions of the manufacturer. cDNA thus obtained was then used as a template for the PCR in a $50 \mu$ reaction volume including a 0.25 $\mu \mathrm{M}$ concentration of each primer, $100 \mu \mathrm{M}$ dNTPs, Taq buffer, and $1 \mu \mathrm{l}$ of Taq polymerase (ATGC Biotechnologies, Noisy-le-Grand, France). The primers used for amplification are listed in supplemental Table 1 (available at www.jneurosci.org as supplemental material). The PCR conditions for analysis of expression of each gene were designed to avoid PCR saturation and to enable semiquantitative determination. Each data point was normalized by the abundance of glyceraldehyde-3-phosphate dehydrogenase (GAPDH) mRNA. For Southern blot analysis, $15 \mu \mathrm{l}$ of the products of each PCR was loaded on a 1\% agarose gel and after electrophoresis transferred onto a Hybond-N nylon membrane (Amersham Biosciences, Arlington Heights, IL) and hybridized overnight at $45^{\circ} \mathrm{C}$ with ${ }^{32} \mathrm{P}$-labeled 20 mer primers. The primers (supplemental Table 1 , available at www.jneurosci.org as supplemental material) were ${ }^{32} \mathrm{P}$ labeled at their $3^{\prime}$ ends by incorporation of $\left[{ }^{32} \mathrm{P}\right] \mathrm{dCTP}$ using terminal transferase (Invitrogen), according to the recommendations of the manufacturer. The blots were washed twice at room temperature with buffer containing $2 \times$ SSC and $0.1 \%$ SDS. Signals were detected by autoradiography. All of the RT-PCR experiments were repeated five times under the same conditions, and, for each gene expression analysis, the PCR was repeated twice with comparable results.

Real-time RT-PCR was performed using an ABI Prism 7700 (Applied Biosystems), and fluorescence detection was performed in 384-well plates using SYBR Green buffer (Applied Biosystems). Primer concentrations were optimized to yield the lowest concentration of primers that gave the same cycle threshold $\left(C_{\mathrm{t}}\right)$ values as recommended by Applied Biosystems. A control RNA sample that was not reverse-transcribed was used with each real-time RT-PCR experiment to verify that there was no genomic DNA contamination. PCR amplification was performed (in triplicate) as a singleplex reaction in a total reaction volume of $25 \mu$ l. The reaction mixture consisted of $12.5 \mu \mathrm{l}$ of SYBR Green template (Applied Biosystems) forward and reverse primers (supplemental Table 1, available at www.jneurosci.org as supplemental material) as determined from the previous optimization procedure, nucleasefree water and cDNA. The PCR parameters were incubation for one cycle at $50^{\circ} \mathrm{C}$ for $2 \mathrm{~min}$ to prevent amplification of carryover DNA, followed by denaturation at $94^{\circ} \mathrm{C}$ for $10 \mathrm{~min}$ and then amplification for 40 cycles of $95^{\circ} \mathrm{C} / 15 \mathrm{~s}$ and $60^{\circ} \mathrm{C} / 1 \mathrm{~min}$. Amplification products were routinely checked using dissociation curve software (Applied Biosystems) and by gel electrophoresis on a $1 \%$ agarose gel and were then visualized under UV light after staining with $0.05 \%$ ethidium bromide to confirm the size of the DNA fragment and that only one product was formed. Samples were compared using the relative $C_{\mathrm{t}}$ method, where the amount of target normalized to the amount of endogenous control and relative to the control sample is given by $2^{-\Delta \Delta C_{\mathrm{t}}}$

Muscle-fiber cross-sectional analysis. Frozen soleus and plantaris muscles from mice were collected and sectioned into $10-\mu \mathrm{m}$-thick sections. Muscle sections were stained with hematoxylin and eosin, dehydrated via an alcohol gradient $(70,90$, and $100 \%)$, and mounted with Eukitt (VWR International, Strasbourg, France). The highest number of myofibers per muscle section was retained for statistical analysis.

Statistical analysis. Statistical comparisons were one-way ANOVA followed by Student's $t$ test. For RT-PCR analysis, all values are pre- 
sented as mean \pm SEM. Survival analysis was performed by KaplanMeier analysis. All data were expressed as mean \pm SEM. For statistical evaluation of motoneuron number, identified by either Nissl staining or ChAT immunoreactivity, the number of cells present in each ventral horn of the L1-L5 spinal cord was counted and corrected according to the method of Abercrombie (1946), which compensates for double counting in adjacent sections.

\section{Results}

\section{Physical exercise prolongs survival in type 2 SMA-like mice}

Forty-five SMA2-like mice were subjected to a regular exercise protocol, which consisted of a forced run in a wheel. The running-based training resulted in remarkable improvement in the survival of type 2 SMA-like mice compared with untrained mice (Fig. 1a). The mean survival increased from $13.7 \pm 2 \mathrm{~d}$ in untrained mice to $21.6 \pm 5.6 \mathrm{~d}$ in trained mice. Survival was extended by $\sim 8 \mathrm{~d}$ after the running-based training, which represented a gain of $57.3 \%$ in lifetime.

The SMA-like mice typically exhibit a body weight reduction that is proportional to the severity of the disease compared with normal mice. The exercise regimen led to a significant and progressive increase of the body weight of the type 2 SMA-like mice until an age of $17 \mathrm{~d}$ (Fig. $1 b$ ). Thereafter, the trained type 2 SMAlike mice manifested a progressive loss of body weight until death.

\section{Physical exercise improves the motor behavior of type 2 SMA-like mice}

To evaluate the motor function benefits induced by the running regimen, we subjected the mice of each group to a grip assay and to an open-field test. In the grip assay, the average time control mice could support their weight by forelimb strength increased regularly, proportionately with age (Fig. $2 a, b$ ). At $12 \mathrm{~d}$ of age, the control mice gripped a hold of the metal rail for $>10 \mathrm{~s}$ (Fig. $2 c$ ). At the same age, the untrained type 2 SMA-like mice were unable to grip. In contrast, the trained type 2 SMA-like mice could grip for $>5 \mathrm{~s}$. At $14 \mathrm{~d}$ of age, the time of gripping exceeded $15 \mathrm{~s}$ for the control mice. The time of gripping remained unchanged for the type 2 SMA-like mice. Near death, the trained type 2 SMA-like mice manifested difficulties in gripping.

We next compared the spontaneous activity of the mice in an open field (Fig. 2d,e). Between 10 and $13 \mathrm{~d}$, the control mice displayed an increase of their locomotion activity, as evidenced by the increase of the total number of crossings and the percentage of peripheral crossings. No significant difference was observed in the behavior of type 2 SMA-like mice at $10 \mathrm{~d}$ in comparison with control mice. At $13 \mathrm{~d}$ of age, untrained SMA-like mice displayed no modification in their locomotion activity and rarely reached the periphery of the field. In contrast, the trained type 2 SMA-like mice, although displaying a significant reduction in the number of crossings in comparison with control mice, displayed a progression of the locomotion activity and nearnormal exploration behavior (peripheral crossings).

\section{Running limits the extent of neuronal loss}

To determine whether running training exerts neuroprotective effects, we counted neurons in the ventral horn of the spinal cord in trained and untrained mice. At $10 \mathrm{~d}$ of age, the type 2 SMA-like mice displayed an $\sim 14.8 \%$ loss of neurons (Fig. $3 a-d$ ). This result is consistent with previous examinations of the spinal cord of SMA-like mice (Hsieh-Li et al., 2000). At $13 \mathrm{~d}$ of age, the neuron loss was massive in the untrained type 2 SMA-like mice, with $\sim 35.1 \%$ reduction compared with the control. Counts of spinal a)
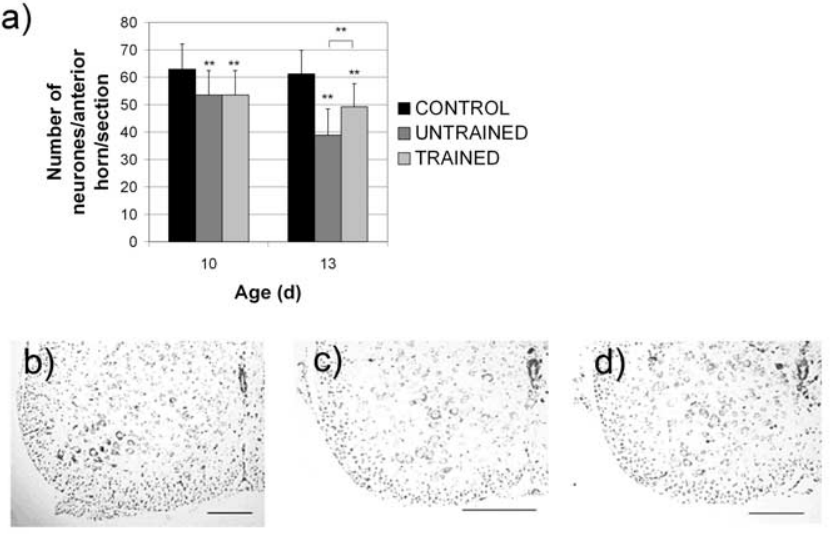

e)
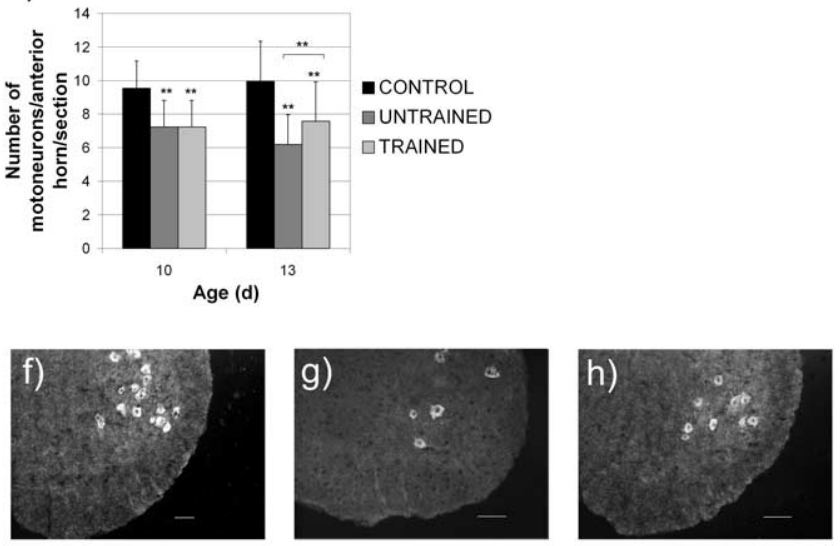

i)

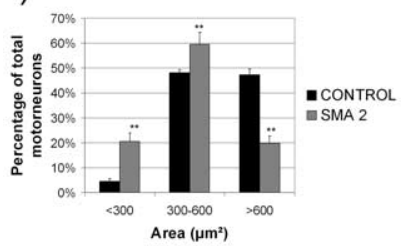

j)

Figure 3. Exercise-induced protection of neurons. $\boldsymbol{a}$, Quantification of surviving neurons in the ventral horn of the lumbar spinal cord (L1-L5) at 10 and $13 \mathrm{~d}$ of age after Nissl staining ( ${ }^{* *} p<0.01$; control, $n=7$ at 10 and at $13 \mathrm{~d}$ of age; untrained type 2 SMA-like mice, $n=12$ at $10 \mathrm{~d}$ of age; $n=8$ at $13 \mathrm{~d}$ of age; trained type 2 SMA-like mice, $n=7$ at $13 \mathrm{~d}$ of age). $\boldsymbol{b}-\boldsymbol{d}$, Histological evaluation of the neuronal loss in the ventral horn of the lumbar spinal cord ( $L 1-L 5)$ at $13 \mathrm{~d}$ of age in control mice $(\boldsymbol{b})$, untrained type 2 SMA-like mice $(\boldsymbol{c})$, and trained type 2 SMA-like mice $(\boldsymbol{d})$. Scale bars, $200 \mu \mathrm{m} . \boldsymbol{e}, \boldsymbol{i}, \boldsymbol{j}$, Determination of the number $(\boldsymbol{e})$ and areas $(\boldsymbol{i}, \boldsymbol{j})$ of motoneurons over the lumbar spinal cord (L1-L5) at 10 and $13 \mathrm{~d}$ of age after ChAT immunostaining. $\boldsymbol{f}-\boldsymbol{h}$, The number of motoneurons was determined in spinal cord removed from control $(\boldsymbol{f})$, untrained $(\boldsymbol{g})$, and trained $(\boldsymbol{h})$ type 2SMA-like mice. Cells were taken into account when exhibiting ChAT immunoreactivity and displaying a large soma $\left({ }^{* *} p<0.01 ;{ }^{*} p<0.05\right.$; control, $n=7$ at 10 and $13 \mathrm{~d}$ of age; untrained type 2 SMA-like mice, $n=9$ at $10 \mathrm{~d}$ of age; $n=8$ at $13 \mathrm{~d}$ of age; trained type $2 \mathrm{SMA}$-like mice, $n=7$ at $13 \mathrm{~d}$ of age). Scale bar, $50 \mu \mathrm{m}$.

cord neurons showed significant protection by exercise in trained type 2 SMA-like mice, with only $19.6 \%$ reduction at $13 \mathrm{~d}$ of age.

To determine whether exercise was beneficial for the motoneurons, we counted the ChAT-positive neurons in the ventral horn of the spinal cord in trained and untrained mice at 10 and $13 \mathrm{~d}$ of age. As shown in Figure $3 e-h$, untrained type 2 SMA-like mice display a substantial reduction in the number of ChATpositive neurons by $10 \mathrm{~d}$ of age (24\% loss) compared with the control mice of the same age. At $13 \mathrm{~d}$ of age, trained mice exhibited significantly greater numbers of ChAT-positive neurons 
a)

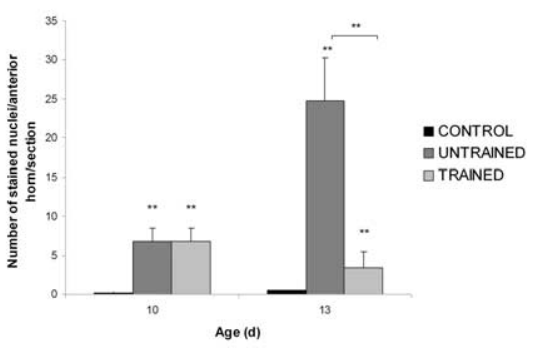

Figure 4. Physical activity reduces the apoptotic process. $\boldsymbol{a}$, Number of apoptotic nuclei in the ventral horn of the lumbar spinal cord (L1-L5) at 10 and $13 \mathrm{~d}$ of age $\left({ }^{* *} p<0.01\right.$; control, $n=7$ at 10 and at $13 \mathrm{~d}$ of age; untrained type 2 SMA-like mice, $n=12$ at $10 \mathrm{~d}$ of age; $n=8$ at $13 \mathrm{~d}$ of age; trained type 2 SMA-like mice, $n=7$ at $13 \mathrm{~d}$ of age). $\boldsymbol{b}, \boldsymbol{c}$, Evaluation of apoptosis by TUNEL (b) staining and DAPI nuclear counterstaining (c) of the lumbar spinal cord in untrained type 2 SMA-like mice at $13 \mathrm{~d}$ of age. Scale bars, $25 \mu \mathrm{m}$.

than in untrained mice ( 75.7 vs $62.6 \%$ of control values, respectively). Because $24 \%$ loss of motoneurons in the trained mice corresponded to the loss initially detected at $10 \mathrm{~d}$ of age in type 2 SMA-like mice, the exercise program likely induced an arrest of the neuron death in the spinal cord.

Cell body area evaluation provided evidence for significant atrophy of motoneurons in the ventral horn of the spinal cord of the type 2 SMA-like mouse at $10 \mathrm{~d}$ of age (Fig. 3i). This atrophy is not reversed after training, as evidenced by the comparison of the cell body areas of motoneurons at $13 \mathrm{~d}$ of age between untrained and trained animals (Fig. 3j).

\section{Running protects neurons from death}

To establish whether training limits the extent of the apoptosis process in neurons, TUNEL staining was performed in the spinal cord of type 2 SMA-like mice at $10 \mathrm{~d}$ of age and in trained and untrained mice at $13 \mathrm{~d}$ of age. TUNEL-positive cells were detected in the ventral horn of the spinal cord of 10-day-old type 2 SMAlike mice (Fig. 4). This result revealed that the apoptotic process was induced in these mutant mice before $10 \mathrm{~d}$ of age, consistent with the counts of neurons presented above. After the training began, the time course of apoptosis was significantly different between trained and untrained mice. Whereas the apoptosis level in trained type 2 SMA-like mice was stable, with fewer than five stained nuclei per ventral horn, the untrained mice showed a dramatic increase of neuronal apoptosis in the spinal cord, with 24.75 stained nuclei per ventral horn. Thus, the neuronal apoptosis in the spinal cord of trained type 2 SMA-like mice processed to a limited extent in comparison with the untrained corresponding animals.

\section{Exercise increases exon 7-containing SMN transcripts in the spinal cord of type 2 SMA-like mice}

Similar to the situation in humans, the transgene SMN2 is alternatively spliced in SMA-like mice. Although the alternative splicing involved three exons, the exons 3, 5, and 7, only the amount of exon 7-containing SMN protein has been shown to be closely related to disease severity in patients as well as in SMA-like mice. To determine whether exercise modifies the expression pattern of the SMN2 gene, and particularly the inclusion of exon 7 compared with the inclusion of exon 5 in SMN transcripts, we performed a semiquantitative RT-PCR and Southern blot analysis using exon-specific primers as probes (supplemental Table 1, available at www.jneurosci.org as supplemental material). The use of primer pairs designed to amplify mRNA containing exons $4-8$ resulted in the production of multiple PCR products from spinal cord RNA samples of 13-day-old trained and untrained type 2 SMA-like mice (Fig. $5 a$ ). We found that the proportion of exon 7-containing transcripts, albeit very low, was significantly higher in trained than in untrained mice. In addition, SMN transcripts lacking both exons 5 and 7 were significantly reduced in trained mice compared with untrained animals. The change in the splicing pattern of exon 7 was further evidenced in a Southern blot hybridized with an exon 7-specific primer (Fig. 5b). No significant difference was observed in the amount of exon-5 containing transcripts in a Southern blot hybridized with the exon 5-specific primer (Fig. 5c). These data clearly indicate a common expression level of the SMN2 gene in the spinal cord of trained and sedentary animals, with an increase in exon 7-containing transcripts in the spinal cord of trained animals.

To quantify more accurately the relative amount of the SMN mRNA variant containing exon 7, we used real time RT-PCR, aimed at amplifying exons 6 and 7. We found a $34.6 \pm 2.3$-fold increase of exon 7-containing SMN mRNA in the spinal cord of trained $(n=13)$ compared with untrained $(n=12)$ type 2 SMAlike mice (Fig. $5 f$ ).

Immunohistochemical detection of SMN protein in the spinal cord of type 2 SMA-like mice clearly indicated a greater level of SMN in trained versus untrained animals at $13 \mathrm{~d}$ (Fig. $5 g-i$ ), as expected regarding the increase of exon 7-containing SMN transcripts in trained mutant animals.

\section{Exercise limits muscular atrophy}

Because weakness is a major cause of disability in SMA, we asked whether the running-induced protection of motoneurons leads to the maintenance of the muscle phenotype. Our counts of neurons were performed in the lumbar spinal cord where the sciatic nerve originates. We then analyzed the phenotype of two muscles of the calf innervated by the sciatic nerve and directly solicited by running, the fast-twitch muscle plantaris and the slow-twitch muscle soleus. Histological examination of the two muscles, by using hematoxylin and eosin staining on transverse sections, revealed a significant reduction in the total number of fibers in type 2 SMA-like mice in comparison with controls (Fig. 6a,b). This muscular hypoplasia was detected as early as $10 \mathrm{~d}$, without any noticeable evolution until death. The exercise program has no effect on the muscular hypoplasia.

We also observed a progressive decrease of the fiber diameter in the two muscles (Fig. $6 c, d$ ), as has been reported previously for tail and limb muscles (Hsieh-Li et al., 2000). A significant decrease could be observed in the average area of muscle fibers from control and type 2 SMA-like mice as early as $10 \mathrm{~d}$ (Fig. 6e,f). Groups of atrophic fibers appeared from $13 \mathrm{~d}$ of age in the two muscles of untrained type 2 SMA-like mice, leading to a dramatic reduction of the average fiber area (Fig. $6 g-i$ ). The exercise program proved to be efficient against muscular atrophy because the average area of the muscle fibers displayed no significant reduction from 10 to $13 \mathrm{~d}$.

To determine whether these different muscular phenotypes were correlated to motoneuron cell protection in the lumbar spinal cord, we compared the counts of fluorogold retrogradely labeled motoneurons projecting into the soleus and plantaris muscles in trained versus untrained type 2 SMA-like mice. At $13 \mathrm{~d}$ 
a)

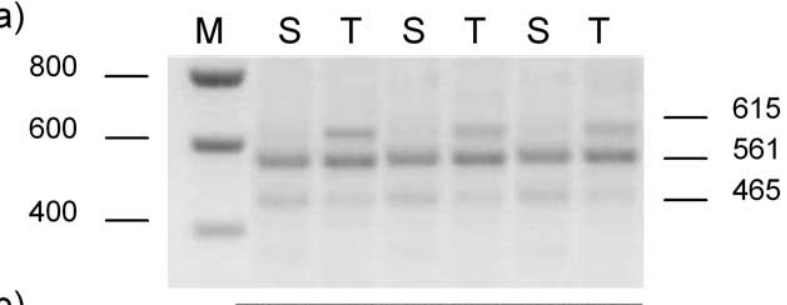

b)

EXON 7

c)

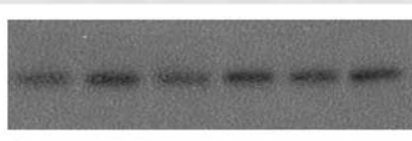

EXON 5

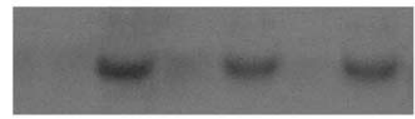

d)

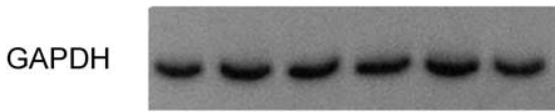

e)
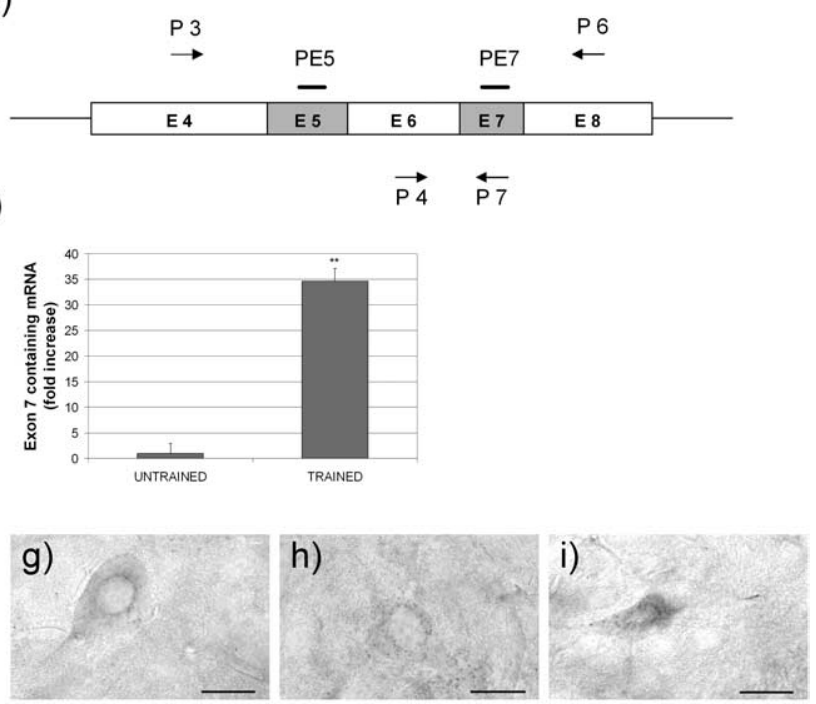

Figure 5. Effects of training on the expression pattern of SMN2 in type 2 SMA-like mice. $\boldsymbol{a}$ RT-PCR analysis of exons 4-8 of SMN2 transcripts showed that the exon 7-containing transcripts were increased in spinal cords of trained mice (T; $n=13)$ in comparison with those of untrained mice $(S ; n=12)$. The 615 -nucleotide $(n t)$-long transcripts are full-length SMN transcripts, whereas 561-nt transcripts lack exon 7, and the 465-nt transcripts lack both exons 5 and 7. Transcripts lacking only exon 5 were not detected in these experiments. M, Length markers. $\boldsymbol{b}$, Hybridization of the RT-PCR products by an exon 7-specific primer highlighting the exerciseinduced increase of full-length SMN transcripts. c, Hybridization of the RT-PCR products by an exon 5-specific primer showing that the splicing pattern of exon 5 remained unchanged after exercise. $\boldsymbol{d}$, RT-PCR and Southern blot of GAPDH. $\boldsymbol{e}$, Central genomic organization of the SMN2 transgene and localization of the primers used for PCR and Southern blot (supplemental Table 1, available at www.jneurosci.org as supplemental material). E, Exon; gray boxes, alternative exons; arrows, primers used for RT-PCR (P3, P6) and real-time RT-PCR (P4, P7); black bars, primers used as probes for hybridization of the Southern blots (PE5, PE7). $f$, Quantification of exon 7-containing transcripts by real time RT-PCR. $\boldsymbol{g}-\boldsymbol{i}$, Immunodetection of SMN protein (clone 2B1) in the spinal cord of untrained ( $\boldsymbol{h}$ ) and trained (i) type 2 SMA-like mice in comparison with control $(\boldsymbol{g})$. Scale bars, $20 \mu \mathrm{m}$.

of age, a dramatic difference in the number of motoneurons labeled with fluorogold could be observed in untrained type 2 SMA-like mice and age-matched control animals (Fig. 7). A 52\% decrease in the cell counts was scored in untrained type 2 SMAlike mice in comparison with age-matched controls $(p<0.01)$. This decrease did not exceed $26 \%$ in trained type 2 SMA-like mice $(p<0.01)$. These data were highly coherent with those obtained a)

b)

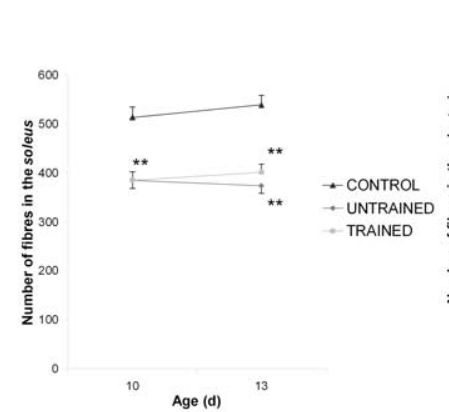

c)

d)
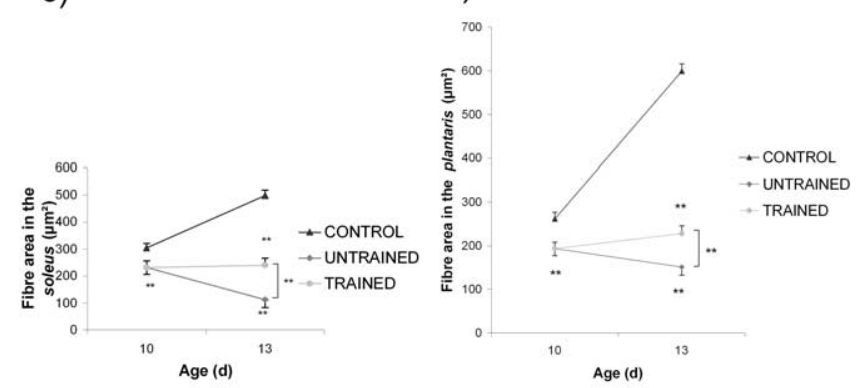
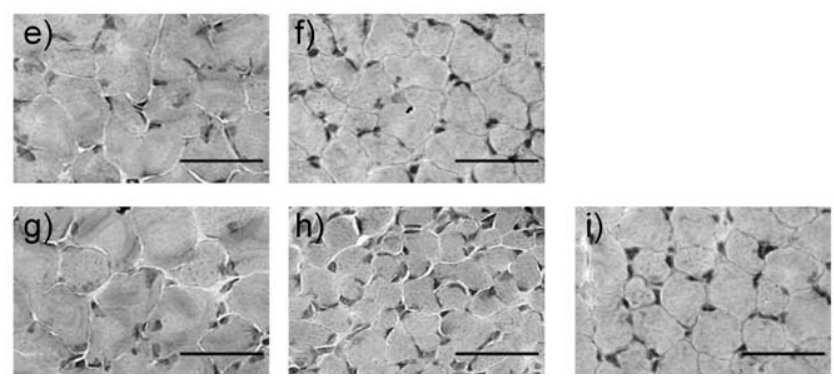

Figure 6. Histological analysis of transverse sections of soleus and plantaris muscles. $\boldsymbol{a}, \boldsymbol{b}, \mathrm{A}$ dramatic loss of muscle fibers was observed in soleus $(\boldsymbol{a})$ and plantaris $(\boldsymbol{b})$ muscles from SMAlike mice in comparison with controls $\left({ }^{* *} p<0.01\right)$. Physical exercise has no effect on this muscle hypoplasia. $\boldsymbol{c}, \boldsymbol{d}$, The analysis of the muscle fiber area in soleus $(\boldsymbol{c})$ and plantaris $(\boldsymbol{d})$ revealed a variation from $10 \mathrm{~d}$ between control and type 2 SMA-like mice $\left({ }^{* *} p<0.01\right)$ and, at $13 \mathrm{~d}$ of age, between untrained and trained mice $\left.{ }^{* *} p<0.01\right) . e, f$, At $10 \mathrm{~d}$, in comparison with controls $(\boldsymbol{e})$, the reduction of the average fiber area is observed in the soleus from type 2 SMA-like mice $(\boldsymbol{f}) . \boldsymbol{f}, \boldsymbol{g}$, At 13 d of age, in comparison with control $(\boldsymbol{g})$, the soleus from untrained type 2 SMA-like mice $(\boldsymbol{f})$ displayed a severe atrophy, which is limited by exercise ( $\boldsymbol{g}$; control, $n=7$ at 10 and $13 \mathrm{~d}$ of age; type 2 SMA-like mice, $n=12$ at $10 \mathrm{~d}$ of age; $n=8$ and 7 for untrained and trained mice, respectively, at $13 \mathrm{~d}$ of age). Scale bars, $20 \mu \mathrm{m}$.

from the neuronal and motoneuronal counts (supplemental Table 2, available at www.jneurosci.org as supplemental material).

\section{Discussion}

Exercise is a simple and widely practiced behavior that activates molecular and cellular cascades that support CNS function, plasticity, and protection against damage. Here, we provide the first evidence that exercise can support the survival of motoneurons in a mouse model of intermediate-type SMA. Forced wheel running has significant beneficial effects on the life span of type 2 SMAlike mice as well as on the associated clinical symptoms. Survival was extended by $57.3 \%$ of life span, which is better than the improvement with sodium butyrate, which extends survival by $39 \%$ in this model, when treatment began just after diagnosis.

Physical exercise participation in nervous system health and 
a)
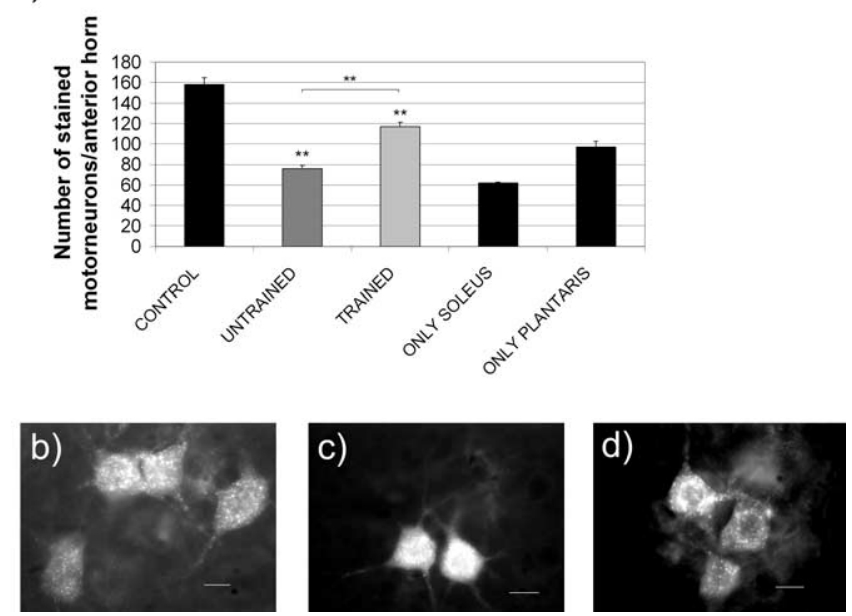

Figure 7. Quantification of the loss of motoneurons innervating the soleus and the plantaris muscles during SMA disease progression using the fluorogold retrolabeling technique. At $13 \mathrm{~d}$ of age, the number of retrogradely labeled motoneurons is 52\% lower in untrained type 2 SMA-like mice compared with controls. With a cell loss of only $26 \%$, the trained type 2 SMA-like mice displayed remarkable neuroprotection ( ${ }^{* *} p<0.01$; control, $n=6$; untrained type 2 SMA-like mice, $n=7$; trained type 2 SMA-like mice, $n=7)$. Scale bars, $25 \mu \mathrm{m}$.

function has consistently emerged as a key factor of plasticity and cell survival. Some of the beneficial effects of exercise act directly on the molecular machinery of nerve cells themselves, in which exercise regulates the expression of a broad array of genes (Tong et al., 2001). Our data show that exercise interferes in some manner with the splicing regulation of the SMN2 gene, rather than its transcriptional activation. Whether this molecular adaptation to exercise causes or is a consequence of the neuroprotection is still unclear. Nevertheless, exercise led to a dramatic increase of the amount of exon 7-containing SMN transcripts in the spinal cord of trained mice, leading to an increase in detectable SMN proteins. The amount of SMN proteins in trained SMA spinal cords likely maintained SMN function in motoneurons, albeit only partially, leading to a significant alleviation of the disease symptoms without abolishing them. This situation could be compared with that of newborn SMA-like mice, in which intact SMN proteins were present in the spinal cord during at least the first week of life (Hsieh-Li et al., 2000), explaining why SMA-like mice develop SMA only after birth. Eventually, the posttranscriptional processing of SMN2 changes in the spinal cord of SMA-like mice, and the extent of this change dictates the disease severity. Thus, the predominant exclusion of exon 7 in motoneurons led to a severe type of SMA. Because we detected an increase of the amount of exon 7-containing SMN transcripts in the spinal cord of trained type 2 SMA-like mice, it can be assumed that the molecular mechanism involved in inclusion of exon 7 was reactivated in trained spinal cord neurons. This hypothesis accounts for the role of exercise in regulating gene expression in neurons.

The molecular mechanism by which exercise exerts its neuronal protection in type 2 SMA-like mice remains to be further elucidated. Exercise might modify the expression pattern of premRNA splicing factors in motoneurons. Which molecules are involved requires additional investigation. The treatment of type 2 SMA-like mice with sodium butyrate, which has been shown to enhance exon 7 inclusion in SMN transcripts, increases the expression of SR (serine-arginine) proteins in spinal cord of treated mice (Chang et al., 2001). Probably, additional factors, other than SR and SR-like proteins, mediate exon inclusion through direct or indirect association with the $S M N$ exon 7 pre-mRNA or interactions with splicing proteins in posttranscriptional processing complexes (Hofmann and Wirth, 2002). Unfortunately, so far, data concerning the effect of exercise on the expression of splicing proteins are lacking. Identifying these factors in trained spinal cord would provide additional insight into the molecular network that is required to form a stable and functional complex on exon 7 during SMN2 pre-mRNA processing. This identification might help develop new tools to delay the progression of SMA symptoms.

Finally, the benefits of the training program are obviously observed at the level of skeletal muscles. The running program limits the extent of muscular atrophy in the soleus and the plantaris muscles of type 2 SMA-like mice. The exercise-induced maintenance of the muscle phenotype is consistent with the better motor capacities of trained mice, as revealed by the behavioral tests. These effects on skeletal muscle fibers might be secondary to the exercise-induced protection of motoneurons. Indeed, the crucial role of nerve activity on muscle growth has been fully illustrated by the dramatic changes induced by motoneuron silencing. Muscle inactivity after spinal cord injury is classically associated with muscle atrophy (Pette and Staron, 2000). Then the exercise-induced arrest of the neuron death in the spinal cord was likely followed by an arrest of the progressive muscle disorders.

Interestingly, we also detected early dramatic hypoplasia in the distal muscles of type 2 SMA-like mice. In SMA, muscle cell loss likely originates from the muscle cells themselves. Indeed, constitutive abnormalities of SMA muscle have been reported using in vivo (Cifuentes-Diaz et al., 2001) and in vitro (GuettierSigrist et al., 1998) models, suggesting primary involvement of muscle cells in the pathology of SMA. Furthermore, defects in the Smn locus result in death of myoblasts in a mouse muscle model of SMA (Nicole et al., 2003). In SMA-like mice, in tissues other than spinal cord, exon 7 is not excluded from SMN transcripts, leading to the expression of full-length SMN proteins at a rate that depends of the number of SMN2 transgene copies (Hsieh-Li et al., 2000). In our experimental conditions, exercise was unable to activate the SMN2 gene transcription. These data may explain why exercise has no effect on muscle hypoplasia in type 2 SMAlike mice.

Our results provide provocative evidence that exercise is beneficial to type 2 SMA-like mice. The exercise regimen should be associated with drug therapy, such as sodium butyrate, to test the possibility of cumulative beneficial effects on the disease progression. It will be important to design training schedules in the other SMA mouse models to examine whether physical exercise is indeed associated with favorable outcomes. These studies would have important implications for developing therapeutic approaches for SMA.

\section{References}

Abercrombie M (1946) Estimation of nuclear population from microtome sections. Anat Rec 94:239-247.

Chang JG, Hsieh-Li HM, Jong YJ, Wang NM, Tsai CH, Li H (2001) Treatment of spinal muscular atrophy by sodium butyrate. Proc Natl Acad Sci USA 98:9808-9813.

Cifuentes-Diaz C, Frugier T, Tiziano FD, Lacene E, Roblot N, Joshi V, Moreau $\mathrm{MH}$, Melki J (2001) Deletion of murine SMN exon 7 directed to skeletal muscle leads to severe muscular dystrophy. J Cell Biol 152:1107-1114.

Guettier-Sigrist S, Coupin G, Braun S, Warter JM, Poindron P (1998) Muscle could be the therapeutic target in SMA treatment. J Neurosci Res 53:663-669.

Hofmann Y, Wirth B (2002) hnRNP-G promotes exon 7 inclusion of sur- 
vival motor neuron (SMN) via direct interaction with Htra2-beta1. Hum Mol Genet 11:2037-2049.

Hsieh-Li HM, Chang JG, Jong YJ, Wu MH, Wang NM, Tsai CH, Li H (2000) A mouse model for spinal muscular atrophy. Nat Genet 24:66-70.

Kirkinezos IG, Hernandez D, Bradley WG, Moraes CT (2003) Regular exercise is beneficial to a mouse model of amyotrophic lateral sclerosis. Ann Neurol 6:804-807.

Klivenyi P, Ferrante RJ, Matthews RT, Bogdanov MB, Klein AM, Andreassen OA, Mueller G, Wermer M, Kaddurah-Daouk R, Beal MF (1999) Neuroprotective effects of creatine in a transgenic animal model of amyotrophic lateral sclerosis. Nat Med 5:347-350.

Lefebvre S, Bürglen L, Reboullet S, Clermont O, Burlet P, Viollet L, Benichou B, Cruaud C, Millasseau P, Zeviani M, Le Paslier D, Frézal J, Cohen D, Weissenbach J, Munnich A, Melki J (1995) Identification and characterization of a spinal muscular atrophy-determining gene. Cell 80:155-165.

Lewin B (1995) Genes for SMA: multum in parvo. Cell 80:1-5.

Liebetanz D, Hagemann K, von Lewinski F, Kahler E, Paulus W (2004) Extensive exercise is not harmful in amyotrophic lateral sclerosis. Eur J Neurosci 11:3115-3120.

Lorson CL, Androphy EJ (2000) An exonic enhancer is required for inclu- sion of an essential exon in the SMA-determining gene SMN. Hum Mol Genet 9:259-265.

Lorson CL, Strasswimmer J, Yao JM, Baleja JD, Hahnen E, Wirth B, Le T, Burghes AH, Androphy EJ (1998) SMN oligomerization defect correlates with spinal muscular atrophy severity. Nat Genet 19:63-66.

Mahoney DJ, Rodriguez C, Devries M, Yasuda N, Tarnopolsky MA (2004) Effects of high-intensity endurance exercise training in the G93A mouse model of amyotrophic lateral sclerosis. Muscle Nerve 5:656-662.

Nicole S, Desforges B, Millet G, Lesbordes J, Cifuentes-Diaz C, Vertes D, Cao ML, De Backer F, Languille L, Roblot N, Joshi V, Gillis JM, Melki J (2003) Intact satellite cells lead to remarkable protection against Smn gene defect in differentiated skeletal muscle. J Cell Biol 161:571-582.

Pette D, Staron RS (2000) Myosin isoforms, muscle fiber types, and transitions. Microsc Res Tech 50:500-509.

Tong L, Shen H, Perreau VM, Balazs R, Cotman CW (2001) Effects of exercise on gene-expression profile in the rat hippocampus. Neurobiol Dis 8:1046-1056

Veldink JH, Bar PR, Joosten EA, Otten M, Wokke JH, van den Berg LH (2003) Sexual differences in onset of disease and response to exercise in a transgenic model of ALS. Neuromuscul Disord 9:737-743. 